\title{
Accident data analysis using Statistical methods -A case study of Indian Highway
}

\author{
Rahul Badgujar ${ }^{1}$, Priyam Mishra ${ }^{2}$, Mayank Chandra ${ }^{3}$, \\ Sayali Sandbhor ${ }^{4}$, Humera Khanum ${ }^{5}$ \\ 1,2,3 Undergraduate scholars, Department of Civil Engineering, \\ Symbiosis Institute of Technology, SIU, Pune, India. \\ 4,5 Assistant Professor, Department of Civil Engineering, \\ Symbiosis Institute of Technology, SIU, Pune, India. \\ 1'rahul.badgujar@sitpune.edu.in, ${ }^{2}$ priyam.mishra@sitpune.edu.in, ${ }^{3}$ mayank.chandra@sitpune.edu.in \\ 4sayali.sandbhor@sitpune.edu.in, ${ }^{5}$ humera.khanum@sitpune.edu.in
}

\begin{abstract}
Road accidents are one of the major causes of death worldwide as per Global safety report more than 1.5 million people are killed in road accidents every year throughout the world[5] The probability of occurrence of accident depends on numerous factors like roadway condition, geometrics of road, vehicle, pavement condition and weather condition, etc[10] each factor contributes its own share towards occurrence of accidents and there can be many more factors which are situation specific. To ascertain the effect of various parameters an accident occurrence, data of road accidents for a stretch of $101 \mathrm{Kms}$ of an Indian national highway was collected for past 3 years. The analysis of the data using regression technique enables to predict the occurrence of accidents for a certain situation and similar application can be carried out on any stretch to get regression equation of similar type.
\end{abstract}

Keywords: Nature of Accidents, Cause of Accidents, Road Feature, Classification of Accident, Road Safety.

\section{INTRODUCTION}

In today's world road and transport has become an integral part of growth and development of a nation. Everybody is a road user in one or other shape. The present transport system has minimized the distance but it has on the other hand increased the life risk. Every road crashed result in loss of lakh of lives and serious to injuries to corers of people. India has a total of about 2 million kilometers of roads out of which 960,000 km are surfaced road and about 1 million $\mathrm{km}$ of roads in India are of poor quality[11]. Rural areas have unsurfaced roads \&urban areas have high severity of congestion. These are some of the major problem face on any Indian roads. This is very serious situation and requires proper attention with the use of some statistical methods. In this study analysis of data is done using regression analysis. In today's world where the number of road commuters is increasing drastically, its demanding more \& more safer roads to have accident free roads. A lot of initiative are being taken up by the government to tackle this issue but needs a little more research attention.

\section{A.Introduction to case study}

As we experience increase in number of vehicles on road simultaneously road accidents are also increasing in same manner. Road accidents are one of the biggest killers in India. Statistics suggests that one person dies in a road accident in India every four minutes [12]. In spite of these numbers being so high, not much effort is made to make roads safer.

National highway (NH9) is a major East - West highway in India \&passes through almost 7 states in present case study analysis data pertaining to accidents on a $101 \mathrm{kms}$ stretch on this highway from Pune to Solapur cities in Maharashtra state of India. Data for 3 years is taken into consideration for analysis. This case study is an effort to make roads safer for road user by using a prediction model developed through regression analysis [6]. 


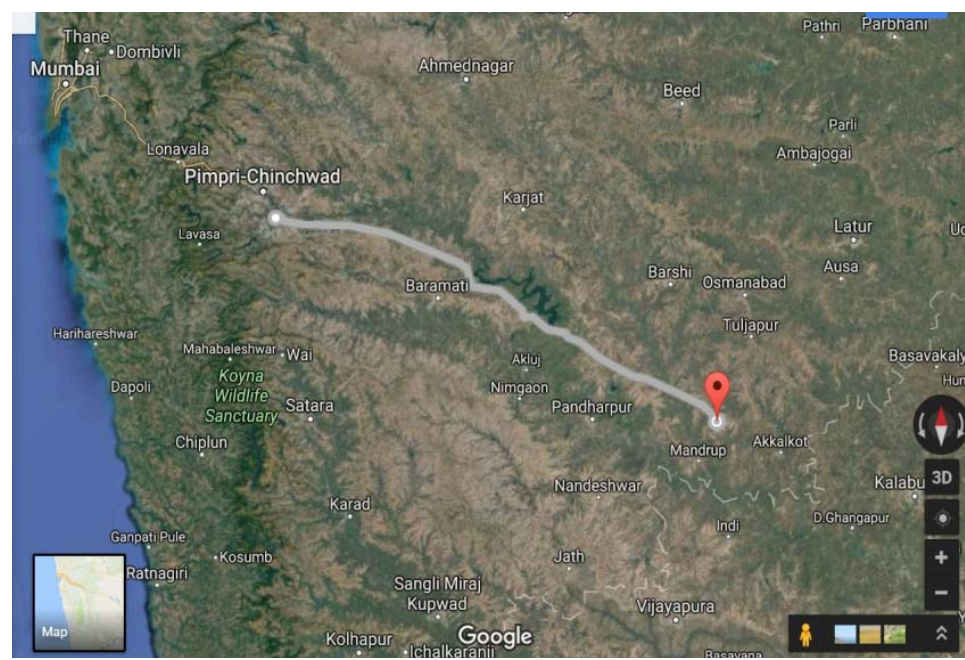

Fig. 1. Study Stretch

\section{RESEARCH METHODOLOGY}

Methodology for the research work is mainly divided into three parts:-

- Analysis based on location - analysis for identifying stretch points with higher number of accidents.

- Analysis based on time - analysis for identifying the hours having highest number of accidents occurring on stretch.

- Regression analysis - for obtaining prediction equation by using parameters available in accidental data.

I. Analysis based on location

For location based analysis stretch is divided into 11 sections for equal length and further divided into right and left lane for analysis. Data is sorted for both lanes and respective accident data for each section is recorded as shown in table 1 .

Table 1. Location Wise Distribution of Stretch

\begin{tabular}{|c|c|}
\hline Section & Accident Location(KM) \\
\hline 1 & $150-159$ \\
\hline 2 & $160-169$ \\
\hline 3 & $170-179$ \\
\hline 4 & $180-189$ \\
\hline 5 & $190-199$ \\
\hline 6 & $200-209$ \\
\hline 7 & $210-219$ \\
\hline 8 & $220-229$ \\
\hline 9 & $230-239$ \\
\hline 10 & $240-249$ \\
\hline 11 & $250 \sim$ \\
\hline
\end{tabular}




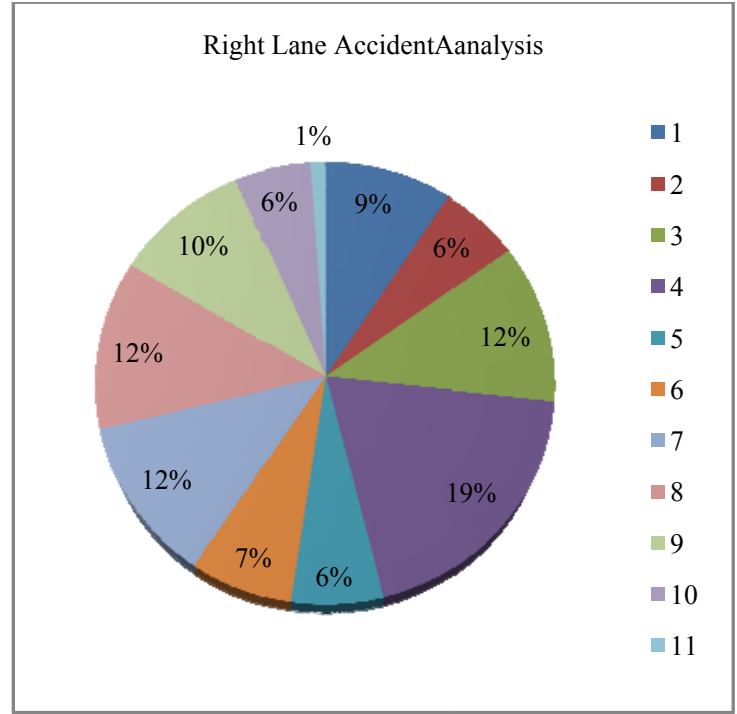

Figure 2: Right Lane analysis

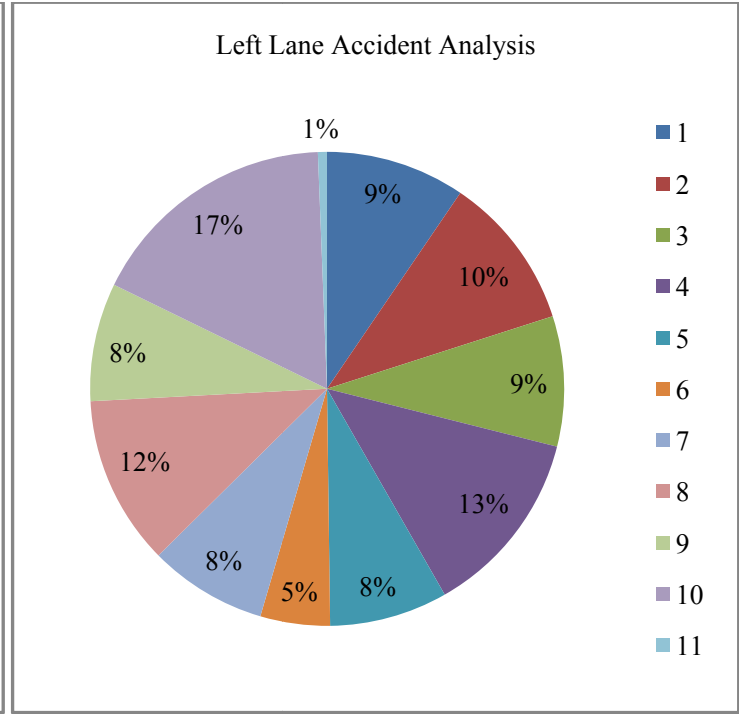

Figure 3: Left Lane analysis

Figure 1 shows \% accidents on right lane section wise \&Figure 2 shows $\%$ accidents on left lane section wise.

II. ANALYSIS BASED ON TIME

For analysis based on time the study stretch is divided into 8 time intervals of 3 hours each and, corresponding number of accident are found out. As available data is for 3 years,year wise sorting is done for in-depth study of accident data and for understanding the pattern for accident data on basis of time represented as $1 \mathrm{~T}$ to $8 \mathrm{~T}$ on the basis of time intervals. [1][7][9]

Table 2. Accident Distribution Based on Time

\begin{tabular}{|c|c|c|c|c|c|c|}
\hline Section & $\begin{array}{c}\text { Time of } \\
\text { Accident }\end{array}$ & $\begin{array}{c}\text { No. of Affected } \\
\text { Persons }\end{array}$ & Fatal & Grevious & Minor & Injury \\
\hline 1T & $00: 00-02: 59$ & 102 & 8 & 16 & 54 & 24 \\
\hline 2T & $03: 00-05: 59$ & 52 & 10 & 21 & 64 & 13 \\
\hline $3 \mathrm{~T}$ & $06: 00-08: 59$ & 56 & 8 & 22 & 84 & 15 \\
\hline 4T & $09: 00-11: 59$ & 139 & 7 & 27 & 74 & 18 \\
\hline 5T & $12: 00-14: 59$ & 126 & 11 & 28 & 70 & 17 \\
\hline 6T & $15: 00-17: 59$ & 162 & 16 & 34 & 82 & 30 \\
\hline $7 \mathrm{~T}$ & $18: 00-20: 59$ & 181 & 14 & 36 & 86 & 38 \\
\hline $8 \mathrm{~T}$ & $21: 00-23: 59$ & 160 & 12 & 38 & 72 & 40 \\
\hline
\end{tabular}

Table 2 shows timewise accident distribution \& gives detailed numbers regardingc classification of accident.

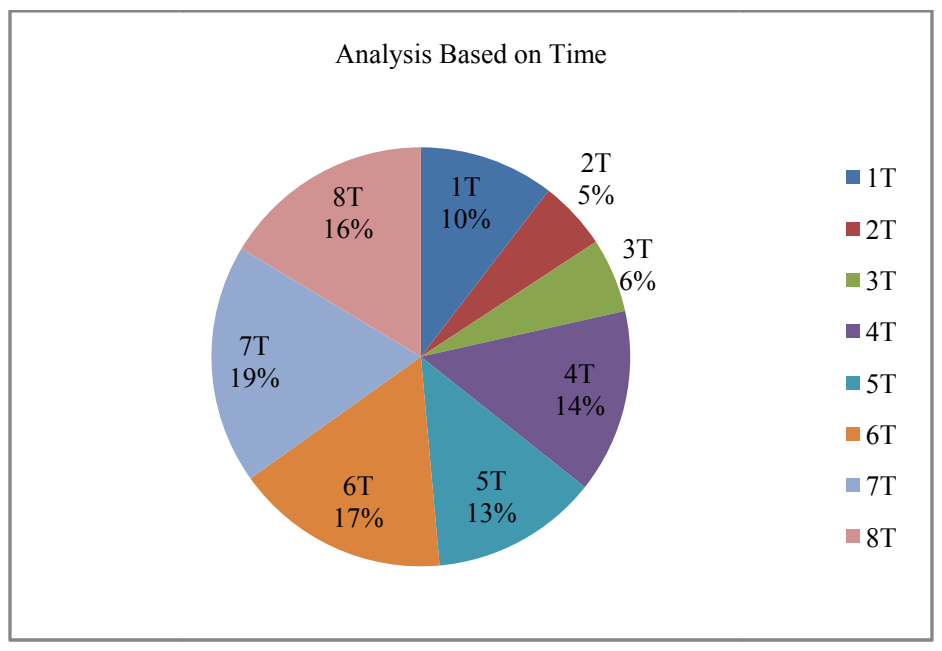

Figure 4: Analysis based on time 
Figure 4 shows \% distribution on basis of time. The available data has been processed to apply regression analysis and predict the accident possibility. Following section explains the same in detail.

\section{REGRESSION ANALYSIS}

The regression model is developed for predicting accident and fatalities, considering factors contributing to occurrence of accidents as independent variables and accident as dependent variable using regression equation.

\section{A. Introduction}

The form for linear regression models developed will be in following form:

$$
y=m x+c
$$

Where,

$\mathrm{y}=$ accident to be predicted.

$\mathrm{x}=$ factor contributing to occurrence of accident.

$\mathrm{m} \& \mathrm{c}=$ slope and coefficient.

For multiple regressions if there are $\mathrm{n}$ predictor variables, then the regression equation model is

$$
y=\beta_{0}+\beta_{1} x_{1}+\beta_{2} x_{2}+\cdots+\beta_{n} x_{n}+c
$$

The $x_{1}, x_{2}, \ldots x_{n}$ represent the $\mathrm{n}$ predictor variables. Those parameters are the same as before, $\beta_{0}$ is the constant, $\beta_{1}$ is the coefficient on the first predictor variable, $\beta 2$ is the coefficient on the second predictor variable, and so on. $\mathrm{c}$ is the error term or the residual that can't be explained by the model.

Microsoft Excel was used to perform the regression analysis on available data.The $\mathrm{df}($ Regression) is one less than the number of parameters being estimated. There are $\mathrm{n}$ predictor variables and so there are $\mathrm{n}$ parameters for the coefficients on those variables. There is always one additional parameter for the constant so there are $n+1$ parameters. But the $\mathrm{df}$ is one less than the number of parameters, so there are $n+1-1=n$ degrees of freedom. That is, the $\mathrm{df}($ Regression $)=\#$ of predictor variables. $[8]$

The $\mathrm{df}$ (Residual) is the sample size minus the number of parameters being estimated, so it becomes $\mathrm{df}$ (Residual) $=m-(n+1)$ or $\mathrm{df}$ (Residual) $=m-n-1$. It is easier just to use subtraction once you know the total and the regression degrees of freedom. Thedf(Total) is still one less than the sample size as it was before. $\operatorname{df}($ Total $)=m-1$. A variance is a variation divided by degrees of freedom, that is $\mathrm{MS}=\mathrm{SS} / \mathrm{df}$. The F test statistic is the ratio of two sample variances with the denominator always being the error variance. So $\mathrm{F}=$ MS(Regression) / MS(Residual).

The null hypothesis claims that there is no significant correlation at all. That is, all of the coefficients are zero and none of the variables belong in the model.The alternative hypothesis is not that every variable belongs in the model but that at least one of the variables belongs in the model. If $p$-value is 0.000 , we must conclude that there is no correlation at all and have a good model for prediction.If the coefficient is zero, then that variable drops out of the model and it doesn't contribute significantly to the model. If the p-value $<0.05$, we'll reject the null hypothesis and retain it otherwise.[13][2][3]

\section{B. Steps for Regression Analysis}

Enter the data into the spreadsheet that you are evaluating. You should have at least two columns of numbers that will be representing your Input $Y$ Range and your Input $X$ Range. Input $Y$ represents the dependent variable while Input $\mathrm{X}$ is your independent variable. Open the Regression Analysis tool. Define your Input $\mathrm{Y}$ Range. Repeat the previous step for the Input X Range. Click OK. The summary of your regression output will appear where designated.

1) Identification of parameters: Total 7 parameters have been identified which are further subdivided into various categories. Dependent and independent variables have been classified (Table 3). Dependent and Independent variables[4]for analysis:-

- Y (dependent variable)

1. Classification of accident

2. Nature of accident

- $\mathrm{X}$ (independent variable)

1. Road feature

2. Intersection type and control

3. Road condition

4. Causes

5. Weather condition 
Table 3. Parameters

\begin{tabular}{|c|c|c|}
\hline Parameters & Categories & Code \\
\hline \multirow{7}{*}{ Nature of Accident (A) } & Overturning & A1 \\
\hline & Head on Collision & $\mathrm{A} 2$ \\
\hline & Rear End Collision & A3 \\
\hline & Collision Brush & A4 \\
\hline & Right Turn on Collision & A5 \\
\hline & Skidding & A7 \\
\hline & Other & A8 \\
\hline \multirow{4}{*}{$\begin{array}{l}\text { Classification of accident } \\
\text { (B) }\end{array}$} & Fatal & B1 \\
\hline & Grievous & B2 \\
\hline & Minor Injury & B3 \\
\hline & Non Injury & $\mathrm{B} 4$ \\
\hline \multirow{5}{*}{ Causes (C) } & Drunken & $\mathrm{C} 1$ \\
\hline & Over Speeding & $\mathrm{C} 2$ \\
\hline & Vehicle Out of Control & $\mathrm{C} 3$ \\
\hline & Fault of Driver & $\mathrm{C} 4$ \\
\hline & Defect in Vehicle & $\mathrm{C} 5$ \\
\hline \multirow{4}{*}{ Road Feature (D) } & Single Lane & D1 \\
\hline & Two Lane & $\mathrm{D} 2$ \\
\hline & $\begin{array}{c}\text { Three Lane or More } \\
\text { Without Central Divider }\end{array}$ & D3 \\
\hline & $\begin{array}{c}\text { Four Lane or More With } \\
\text { Central Divider }\end{array}$ & D4 \\
\hline \multirow{8}{*}{ Road Conditions (E) } & Straight Road & E1 \\
\hline & Slight Curve & E2 \\
\hline & Sharpe Curve & E3 \\
\hline & Flat Road & E4 \\
\hline & Gentle Slope & E5 \\
\hline & Steep Slope & E6 \\
\hline & Hump & E7 \\
\hline & Dip & E8 \\
\hline \multirow{8}{*}{$\begin{array}{l}\text { Intersection Type and } \\
\text { Control }(\mathrm{F})\end{array}$} & T Junction & F1 \\
\hline & Y Junction & F2 \\
\hline & Four Arm Junction & F3 \\
\hline & Staggered Junction & F4 \\
\hline & $\begin{array}{c}\text { Junction with More Than } \\
\text { Four Arms }\end{array}$ & F5 \\
\hline & Roundabout Junction & F6 \\
\hline & Manned Rail crossing & F7 \\
\hline & Unmanned Rail Crossing & $\mathrm{F} 8$ \\
\hline \multirow{5}{*}{ Weather Conditions (G) } & Fine & G1 \\
\hline & Mist /Fog & $\mathrm{G} 2$ \\
\hline & Cloud & G3 \\
\hline & Light Rain & G4 \\
\hline & Hail & G5 \\
\hline
\end{tabular}




\begin{tabular}{|c|c|c|}
\hline \multirow{4}{*}{} & Snow & G6 \\
\cline { 2 - 3 } & Strong Wind & G7 \\
\cline { 2 - 3 } & Dust Storm & G8 \\
\cline { 2 - 3 } & Very Hot & G9 \\
\cline { 2 - 3 } & Very Cold & G10 \\
\hline & $\begin{array}{c}\text { Other Extraordinary } \\
\text { Weather Conditions }\end{array}$ & G11 \\
\hline
\end{tabular}

For regression analysis following parameters are choose on basis of correlation and regression is applied using Microsoft Excel (2007).

\section{Application of regression analysis}

$y=$ Classification of accident, $x_{1}=$ Road Feature, $x_{2}=$ Road Condition, $x_{3}=$ Intersection Type and Control, $x_{4}$ $=$ Weather Condition

Table 4 below shows the results of application of regression analysis.

Table 4. Summary Output

\begin{tabular}{|c|c|}
\hline Regression & Statistics \\
\hline Multiple R & 0.162933 \\
\hline R Square & 0.265473 \\
\hline Adjusted R Square & 0.018821 \\
\hline Standard Error & 0.824064 \\
\hline Observations & 634 \\
\hline
\end{tabular}

\begin{tabular}{|c|c|}
\hline & Coefficients \\
\hline Intercept & 2.460882533 \\
\hline$x_{1}$ & -0.003573306 \\
\hline$x_{2}$ & 0.016035055 \\
\hline$x_{3}$ & -0.017147712 \\
\hline$x_{4}$ & 0.009261565 \\
\hline
\end{tabular}

\begin{tabular}{|l|l|l|l|l|l|}
\hline & df & SS & MS & SF & Significance F \\
\hline Regression & 4 & 11.66725968 & 2.333452 & 3.436185 & 0.00451679 \\
\hline Residual & 630 & 427.821734 & 0.679082 & & \\
\hline Total & 634 & 439.4889937 & & & \\
\hline
\end{tabular}

From regression analysis output we obtain coefficients for parameters and obtained equation is:

$$
y=\left(-0.00357 x_{1}+0.016035 x_{2}-0.01715 x_{3}+0.009262 x_{4}\right)+2.460883
$$

\section{Prediction}

Using the equation form from regression analysis of accidental data prediction is made for different independent variables along the stretch so as to find classification of accident that can occur. Validation of prediction model is done using available accident data. Error in respective model is indentified and their validity is checked (Table 5).

Table 5. Prediction for classification of accident

\begin{tabular}{|c|c|c|c|}
\hline $\begin{array}{c}\text { Predicted } \\
\text { Value }\end{array}$ & $\begin{array}{c}\text { Classification of } \\
\text { Accident (Actual Value) }\end{array}$ & Difference & Accuracy (\%) \\
\hline 2.856232 & 3 & -0.143768 & 95.2077333 \\
\hline 2.872267 & 3 & -0.127733 & 95.7422333 \\
\hline 0.571827 & 1 & -0.428173 & 57.1827 \\
\hline 4.091291 & 4 & 0.091291 & 98.1808 \\
\hline 3.030221 & 3 & 0.030221 & 99.6101 \\
\hline 2.856232 & 3 & -0.143768 & 95.2077333 \\
\hline
\end{tabular}




\section{OBSERVATIONS}

Analysis based on accident location predicts $180-189 \mathrm{~km}$ on right lane have highest no of accidents on study stretch. Analysis based on accident location predicts $240-249 \mathrm{~km}$ on left lane have highest no of accidents on study stretch. Analysis based on time predicts 18:00-20:59 hrs have highest no of accidents on study stretch. Using prediction equation and proper parameters, prediction for classification of accident that can take happen on stretch can be made. For prediction purpose, random 60 values from available accident data is chosen for input variables and prediction is made using equation. Predicted values from regression equation were compared with available accident data and found that prediction model for classification of accident predicts $66 \%$ values with an error of approx $10 \%, 12 \%$ values with an error of $20 \%$ and $22 \%$ values with an error higher than $30 \%$.Using field details of stretch and prediction model potential points for accidents can be predicted.

\section{CONCLUSION}

Severity of accident can be reduced by applying prediction model with proper input of parameters. The likelihood of accidents on the study stretch can be reduced. The need of costly remedial work can be reduced. The total cost of stretch safety for community, including accidents, disruption and trauma is minimized. Safety provisions needed for KM180-189 on right lane and on KM240-249 on left lane as these have highest no. of accidents. Lighting provisions must be improved for 18:00-20:59 hrs on study stretch.

\section{ACKNOWLEDGMENT}

We would like to express our sincere gratitude to our guide Ms. Sayali Sandbhor for providing her valuable guidance, comments and suggestions throughout the course of the project. We would also like to thank Mrs. Humera Khanum for introducing us the topic and providing data.

We are really grateful towards our college for providing us all the necessary permissions and details we required. The faculty was also very helpful for any of our doubts related to project.

\section{REFERENCES}

[1] Accident Analysis on NH-18 by Using Regression Model and its Preventive Measures VeluruSailaja1 , Dr. S. Siddi Raju2

[2] Road Accidents Study Based On Regression Model: A Case Study of Ahmedabad City ManishaMinesh Desai

[3] Accident Analysis and Prediction of Model on National Highways Rakesh Kumar Singh \& S.K.Suman

[4] Analysis of relationship between road safety and road design parameters of four lane National Highway in India Ravi Shenker1,Arti Chowksey2 and HarAmrit Singh Sandhu3

[5] http://www.who.int/violence_injury_prevention/road_safety_status/2015/en/

[6] Wikipedia

[7] Transport Research Wing of the Ministry of Road Transport and Highways

[8] SAS

[9] Big sky

[10] AASHTO

[11] www.badroadsinindia.com

[12] http://timesofindia.indiatimes.com/topic/Road-accident

[13] https://people.richland.edu/james/ictcm/2004/multiple.html

\section{AUTHOR PROFILE}

Author1 Rahul Badgujar Undergraduate scholar, Department of Civil Engineering, Symbiosis Institute of Technology, SIU, Pune, India

Author2 PriyamMishra Undergraduate scholar, Department of Civil Engineering, Symbiosis Institute of Technology, SIU, Pune, India

Author3 Mayank Chandra Undergraduate scholar, Department of Civil Engineering, Symbiosis Institute of Technology, SIU, Pune, India

Author4 Sayali Sandbhor Assistant Professor, Department of Civil Engineering, Symbiosis Institute of Technology, SIU, Pune, India

Author5 Humera Khanum Assistant Professor, Department of Civil Engineering, Symbiosis Institute of Technology, SIU, Pune, India 